\title{
JUIZ LEIGO NO JUIZADO ESPECIAL CRIMINAL - PRIMEIRAS NOTAS
}

\author{
André Alexandre Happke ${ }^{1}$
}

Resumo: Com a Lei n. ${ }^{0}$ 9.099/95 passamos ao desenvolvimento de um "microssistema", hoje, já um "Sistema de Juizados Especiais". Nele, além de novos ritos, regras e novo delineamento de princípios, também veio um novo agente: o Juiz Leigo. A mesma norma tratou do procedimento Cível e do Criminal. Em ambos, é prevista expressamente o Juiz Leigo a par do Conciliador. São atribuições distintas a cada um, requisitos distintos para investidura. Ambos assumem importância ímpar para que esse novo espaço não seja apenas "mais uma nova forma de fazer tudo igual”. A proposta aqui é entender o Juiz Leigo na seara criminal.

Palavras-chave: Juizado Especial Criminal. Juiz Leigo. Jurisdição

\section{INTRODUÇÃO}

Há um debate presente no meio jurídico sobre a possibilidade de atuação do Juiz Leigo no Juizado Especial Criminal, em especial em sua fase instrutória e decisória².

\footnotetext{
1 Juiz de Direito do Tribunal de Justiça do Estado de Santa Catarina. Responsável pelo $2^{\circ}$ Juizado Especial Cível da Comarca de Joinville e $2^{\circ}$ Membro da $5^{a}$ Turma Recursal de Juizados Especiais Cíveis, Criminais e da Fazenda Pública, com sede na mesma Comarca. É Mestre em Ciência Jurídica. Docente da Academia Judicial do Poder Judiciário do Estado de Santa Catarina. (E-mail: andre@amc.org.br)

2 Só para notícia e registro, exemplificando, há o Processo Administrativo n. ${ }^{\circ} 458162$ 2012.8 tramitando perante o Conselho Gestor do Sistema de Juizados Especiais e Métodos Não Adversariais de Resolução de Conflitos do Tribunal de Justiça do Estado de Santa Catarina. Nos votos que já o compõe (trata-se de procedimento não finalizado) percebe-se a existência de vários procedimentos, pedidos e providências em andamento a respeito da questão.
} 
Inicialmente, apresentemos o Juiz Leigo. É Bacharel em Direito que não pertence aos quadros da Magistratura (não é "Juiz togado" ${ }^{3}$ e que exerce atividade remunerada ou voluntária ${ }^{4}$. Sua previsão legal veio com a Lei n. ${ }^{\circ}$ 9.099/95 (Lei dos Juizados Especiais Cíveis e Criminais - LJE). Poderia dizer mais sobre os requisitos para sê-lo neste momento, mas isso levaria a outras discussões que a este texto não pertencem, embora igualmente relevantes.

O Juiz Leigo, perante o Juizado Cível, importante o paralelo, além de tentar conciliar as partes, pode ouvir as testemunhas em audiência instrutória (coleta de prova) e ainda pode elaborar uma peça processual que alguns chamam de sentença, outros de decisão, outros de minuta de decisão ou sentença. Quanto a esta peça processual, diga-se, se assemelha a um parecer sobre o caso, com a proposta de uma solução jurídica. De posse dessa peça, caso o Juiz de Direito (togado) com ela concorde e entenda que nenhum outro ato de prova ainda seja necessário para formar sua convicção (do Juiz de Direito), ele então a homologará (esta é a previsão legal). Dessarte, na prática a peça assume o papel da fundamentação pelo Juiz de Direito, com relação à decisão (judicial, do Juiz de Direito) que se segue. Cumpre-se, pois, o mandamento constitucional da fundamentação expressa da decisão judicial ${ }^{5}$, ainda que por "adoção" do fundamento proposto pelo Juiz Leigo 6 .

Pois bem, a celeuma não está no Juiz Leigo no cível. Ou ao menos não deve estar.

3 Nesse contexto, "Juiz togado" seria o Magistrado, aquele assim denominado na Lei Orgânica da Magistratura (LC n. ${ }^{\circ}$ 35/79), previsão a ser lida conforme o art. 92 da Constituição vigente.

4 Em Santa Catarina, não existe ato normativo que preveja a remuneração, em que pese a existência de estudos a respeito perante o Conselho Gestor do Sistema de Juizados Especiais e Métodos não-Adversariais de Resolução de Conflitos. No nosso caso, portanto, o Juiz Leigo (por enquanto) é apenas um Voluntário.

5 A referência aqui é ao inc. IX do art. 93 da Constituição vigente.

6 Não é demais referir que isso não é completamente pacífico. Há quem entenda que não cumpre a fundamentação a adoção de conteúdo, por exemplo, de parecer ministerial. Cientificamente, tecnicamente, a discussão pode ser em diversos planos. Todavia, é uma prática arraigada (tanto quanto controversa) que se observa inclusive (só para registrar pelo ápice) no Supremo Tribunal Federal. 
Há questionamentos com relação ao que seria o Juiz Leigo perante o Juizado Especial Criminal. Não se desconhece que há decisões administrativas e jurisdicionais em Tribunais e também no Conselho Nacional de Justiça que tangenciam o tema. O objetivo deste pequeno estudo não é dissecá-las, tampouco rejeitá-las, aceitá-las ou ignorá-las. O que se busca aqui é um esforço argumentativo a respeito, sem vinculação com essas tomadas de posição (argumento de autoridade).

Nestes apontamentos, passarei ao largo da fundamentação sobre a necessidade de se ter Conciliadores e Juízes Leigos nos Juizados Especiais, pois isso seria apenas um fundamento de reforço e não propriamente o ponto nodal.

A discussão sobre a configuração jurídica desse agente (Auxiliar da Justiça) teria de passar por dois caminhos necessários. Esses caminhos, veja-se, sequer se ligam diretamente à face de Juizado Criminal. Pertencem igualmente à face de Juizado Cível, contudo, neste há menos discussão instalada.

Um desses caminhos seria trabalhar o motivo de existir expressa menção legal (e constitucional) à atuação de Juiz Leigo (além de Conciliador) nos Juizados Criminais. Sabe-se que a lei não tem (ou não deve ter) palavras inúteis (regra hermenêutica básica). Então, seria necessário inicialmente superar a existência de algo que diferencie a atuação do Juiz Leigo e do Conciliador, do contrário, bastaria o Conciliador (caso não pudesse instruir e/ou propor decisão o Juiz Leigo, atividades estas que não são atribuídas de forma alguma ao Conciliador).

Cabe lembrar que para o Juizado da Fazenda Pública ${ }^{7}$, co-irmão do mesmo Sistema, o Conciliador pode mesmo coletar prova ${ }^{8}$. Não pretendo aqui avançar nisso, mas é importante observar como se está evoluindo neste novel Sistema (de a coleta da prova ser feita por outros agentes).

Superada essa questão - veja que é apenas tratada "de passagem" aqui, mas é algo profunda o suficiente para ensejar 
muito texto em outro momento - vem a necessidade de delinear que um dos fundamentos por vezes trazidos a lume pelos que são contra a atuação do Juiz Leigo no crime é a inafastabilidade da jurisdição, do juiz natural etc.

Para abordar isso, em notas primeiras, sem qualquer intenção de esgotar o assunto, mas antes, de invocar a discussão, tenho que há de se separar, inicialmente, três momentos da atuação de um Juiz Leigo: instruir em audiência; decidir em audiência; elaborar a peça a ser homologada pelo Juiz de Direito.

\section{O JUIZ LEIGO E A "INSTRUÇÃO"}

Conquanto exista algum debate sobre as diferenças (não apenas semânticas) entre "supervisionar" uma audiência, "conduzir" uma audiência ou "presidir" uma audiência, o fato é que sempre, isso é indiscutível, haverá um Juiz de Direito responsável pelo processo judicial em todos os momentos, desde a chegada do Termo Circunstanciado da Delegacia até o despacho de arquivamento definitivo depois de tudo decidido e resolvido e cumprido. Este Magistrado é o "juiz natural”, aquele do princípio que tem esse rótulo. Há, pois, um "Juiz de Direito do processo". Isso (também) é cumprimento do princípio da inafastabilidade da jurisdição. E veja-se que há quem pretenda que essa "jurisdição" passe aos Delegados de Polícia (me refiro a um Projeto de Lei em trâmite no Congresso Nacional $^{9}$, o que é outra discussão que a este espaço não pertence ${ }^{10}$ ).

Esse instruir, em sua essência, é coletar as provas necessárias ao convencimento para a decisão. Há “instrução” pelas partes quando trazem documentos que serão juntados (provas, laudos etc.) e há "instrução" também quando se ouvem as testemunhas que as partes arrolaram. Essa oitiva hoje é protagonizada pelas próprias partes (por meio dos profissionais Advo-

9 Projeto de Lei n. ${ }^{\circ} 133 / 2011$, que tramita no Senado.

10 Vide Nota Técnica da Associação Nacional dos Procuradores da República a respeito, publicada no site Consultor Jurídico, dentre outras fontes, que referencio ao final. 
gado e Promotor), que iniciam as perguntas, ficando apenas um "resíduo" de algo eventualmente não esclarecido para o Juiz ao final. Essa é a ótica atual do sistema do Processo Penal no que também ilumina o funcionamento do Juizado Especial Criminal.

Não é demais lembrar que há ordenamentos em que essas oitivas sequer acontecem em ambiente forense. Ocorrem nos próprios escritórios de Advogados e nas Promotorias, com a participação em alguns casos do Escrevente oficial do Juízo, que toma as notas. É uma evolução que alcançará nosso ordenamento futuramente, é possível crer, até pela celeridade que ela proporciona, sem que essa prova que normalmente é a mais precária de todas (a testemunhal) é a que mais faz demorar a prestação jurisdicional, condicionada à escassa pauta de um Juiz de Direito (em juízos comuns) e a inúmeros percalços na localização de pessoas e também da lembrança que elas têm dos fatos. Sem falar na "valorização" da atuação de Advogados e Promotores, na fé que se dá à sua atuação dentro do processo.

Nesse passo, é por demais importante que se compreenda a possibilidade de que nessa coleta de prova possa atuar o Juiz Leigo, a quem restará o "resíduo" daquilo que não tenham perguntado acusação e defesa, não podendo sequer assumir perguntas de conteúdo direcionado, o que tem se considerado inclusive nulidade, por quebra da nova "ordem" de funcionamento do Processo Penal (na atuação de Juízes de Direito, inclusive). O que faz então o Juiz Leigo ao coletar a prova? $\mathrm{O}$ que em outros lugares se faz em escritórios: conduz as oitivas para adequado registro, tendo Advogado e Promotor como protagonistas dos questionamentos levados a efeito perante as testemunhas. Tais depoimentos (agrego este comentário local/regional) aqui em Santa Catarina são gravados em sistema audiovisual, possibilitando em todo caso que o Juiz de Direito (que não esteja presente ao ato da audiência) veja com clareza como foi o andamento dos depoimentos, seu conteúdo, a segurança/ insegurança da testemunha, tudo o mais que entenda neces- 
sário para formar seu convencimento. A decisão, absolutória ou condenatória, invariavelmente será do Juiz de Direito.

Esse é um dos pontos pelos quais o debate precisa passar: é possível no estágio atual das coisas abrir mão da figura do Juiz Leigo como "coletor de provas" ou não? É "ato jurisdicional" propriamente fazer eventualmente perguntas residuais ao final? Apenas nos ordenamentos que admitem os depoimentos fora de ambiente forense é que isso não seria "ato jurisdicional"? Afinal, não pode ser lá e não ser cá. Ou lá se admite que Advogados e Promotores pratiquem "ato jurisdicional" de coletar depoimentos ou nem lá nem cá isso é "ato jurisdicional" propriamente.

Não é demais lembrar que nos processos em que é admitida, a prova pericial, que assume uma importância considerável, justamente por ser técnico-científica, é feita apenas na presença das partes e não do destinatário da prova: o Magistrado. Nem por isso se lhe retira a validade. Pelo contrário, se dizem que a prova testemunhal é a prostituta das provas, a rainha das provas é a pericial.

Antes que alguém - que não convive com o Sistema de Juizados Especiais - se pergunte por que motivo seria necessário ter Juízes Leigos coletando prova, basta ver que antes do Juizado Especial Criminal (Lei n. ${ }^{\circ}$ 9.099/95) a maior parte dos delitos de menor potencial ofensivo tinha um caminho certo: prescrição. Ou então, alimentavam a fila dos assim reconhecidos "delitos de bagatela" simplesmente, gerando um sentimento/ resultado comum: impunidade.

De outra ponta, nem de longe há estrutura adequada de funcionamento em todos os Juizados Especiais Criminais (onde existem e não são apenas cumulação do trabalho de um Juízo Comum). Assim, normalmente há ainda o problema da possibilidade da prescrição. Além disso, a que custo se teria um Juiz de Direito (ou outro Servidor remunerado, seja qual fosse) deslocado para essa atividade direta quando sua força de atuação é em muito multiplicada pela existência dos agentes que carac- 
terizam o funcionamento dos Juizados Especiais (Voluntários Conciliadores e Juízes Leigos). A grande diferença de resultados de unidades da Justiça Comum e Juizados (onde há essa diferença) é justamente a multiplicação das frentes de trabalho pela atuação desses peculiares personagens. Alarga-se, em muito, a capacidade de absorção das demandas, que nem por isso deixam de ser ao final apreciadas por um Magistrado.

\section{DECISÕES EM AUDIÊNCIA}

Ao Juiz Leigo é atribuída a possibilidade de decidir na hora, em audiência, sobre os incidentes que possam impedir a continuidade da instrução ${ }^{11}$. E só. Todo o mais é atividade reservada ao Juiz de Direito.

Faculto, ad argumentandum, interpretação mais restritiva do que a acima referida e fundamentada em rodapé. Havendo necessidade de decisão interlocutória durante a coleta da prova pelo Juiz Leigo, poderia ser obrigatória então a vinda do Juiz de Direito para decidir a respeito, retornado-se então o ato à condução pelo Juiz Leigo. O Juiz Leigo sempre, inafastavelmente, supervisionado pelo Juiz de Direito (sob sua orientação, sob suas ordens, conforme o entendimento do togado etc.).

Além disso, o Juiz de Direito, com a instrução concluída, no momento de julgar/decidir poderá reabrir a instrução caso entenda que não foi coletada alguma prova que julgue necessária ao seu convencimento, ou que alguma questão essencial não foi feita, ou seja, que algo precisa complementação.

11 Isso considerados o art. 29 da Lei n. ${ }^{\circ}$ 9.099/95 e o Enunciado Cível n. ${ }^{\circ} 33$ do Fórum Estadual de Juizados Especiais do Estado de Santa Catarina (FEJESC). In verbis: "Lei n. ${ }^{\circ}$ 9.099/95, art. 29. Serão decididos de plano todos os incidentes que possam interferir no regular prosseguimento da audiência. As demais questões serão decididas na sentença"; "Enunciado Cível n. ${ }^{\circ} 33$ do FEJESC - Estende-se a hipótese do art. 29 da Lei n. 9.099/95 ao Juiz Leigo". Atento para o fato de que estou referindo a Enunciado Cível, mas ele se refere justamente ao que diferencia Juiz Leigo de Conciliador, que é a atividade de coleta da prova (além, claro, da proposta de decisão). É certo, de todo modo, que não preclui essa decisão, pois ela depende para sua operação/validade a homologação do Juiz de Direito. 
Nada do que foi decidido em audiência pelo Juiz Leigo preclui - repiso, apenas decisões sobre o andamento da coleta de provas. Nada que ele decida fica fora da apreciação jurisdicional, inclusive, por não haver recurso cabível contra decisões interlocutórias e as questões estarem ainda "pendentes" quando do momento do julgamento em primeira instância (como também em grau superior).

\section{ELABORAÇÃo DA PEÇA A SER HOMOLOGADA PELO JUIZ DE DIREITO}

Não se pretende aqui esgotar esse tema. É algo tortuoso e se poderia adotá-lo para uma monografia ou mesmo dissertação de mestrado, de tanto que se pode falar sobre ele: a natureza jurídica do teor dessa peça produzida pelo Juiz Leigo.

Sentença? Decisão? Minuta, proposta?

Seja qual for a resposta, de uma coisa não se tem dúvida: não tem qualquer efeito jurídico, por mais remoto que seja, sem que um Juiz de Direito a homologue.

Enquanto um parecer ministerial, uma alegação final da defesa, são atos jurídicos perfeitos e completos, cumprem completamente seu papel sem que dependam para sua validade ou eficácia que o Juiz de Direito decida sobre o que disseram esses agentes, tal não ocorre - não há a menor dúvida - com a peça vinda do Juiz Leigo.

Ela sequer deve ser juntada ao processo antes de ser homologada pelo Juiz de Direito, opinião pessoal deste que escreve.

Não tem existência no campo do direito sem a homologação judicial. Essa homologação é (sob uma ótica possível) a "adoção" desta "proposta" como fundamento e razão de decidir.

Ninguém tem a menor nesga de dúvida a respeito do fato que não sendo homologada, jamais, nunca, poderá ser cumprida: seja condenatória, seja absolutória. Simplesmente não opera efeito algum. 
Assim, é absolutamente inapropriado falar em "jurisdição” pelo Juiz Leigo. Não há qualquer jurisdição. Essa é e continua sendo exclusiva do Juiz de Direito (togado), pois sem o ato de homologação, este que efetivamente absolverá ou condenará (com os fundamentos vindos da peça produzida pelo Juiz Leigo), nenhum efeito advém.

Veja-se que, como já antes dito, é possível adotar um parecer ministerial como razão de decidir (embora de técnica questionável no campo científico, acontece na prática) e, nem por isso, alguém cogita de que houve "jurisdição" pelo Promotor de Justiça quando isto acontece. Da mesma forma, não há jurisdição no Juiz Leigo.

\section{CONCLUSÃO}

Nessas poucas linhas sobre um tema que tenho por importante, que trata da viabilidade de funcionamento em tempo razoável, com a economicidade adequadamente equacionada e, ainda, observados todos os demais princípios que norteiam não apenas o Sistema de Juizados como todo o resto do ordenamento jurídico, trago algumas considerações que não se poderiam rotular de "conclusões". Como no início dito, são mais "provocações” à reflexão.

5.1. A quantidade de "decisões interlocutórias" em audiência a demandar essa discussão sobre poderem ser proferidas pelo Juiz Leigo ou necessariamente pelo Juiz de Direito é tão diminuta na massa de instruções levadas a efeito que se percebe que não é o principal ponto a defender, embora seja algo que também precise ser trabalhado.

5.2. A utilização ou não da "proposta" de decisão pelo Juiz Leigo, tratada no item 3, além de ser uma faculdade ao Juiz de Direito, e ser uma boa contribuição à solução breve e também se agregar mais uma posição imparcial de visão sobre o litígio antes da fala jurisdicional do Magistrado, pode mesmo não ser utilizada e ser relegada a segundo plano, isso caso os opositores da 
atuação do Juiz Leigo no Juizado Criminal prevaleçam ao final. Ainda assim, é excelente contribuição de quem presenciou a coleta da prova e tem conhecimento jurídico.

5.3 O mais importante na atuação do Juiz Leigo, como contribuição para o andamento célere e em tempo razoável de duração, e observado o devido processo legal que o nomina diretamente na Constituição para tal fim, é justamente multiplicar a força de coleta da prova, seja coligindo as oitivas de testemunhas protagonizadas pelos Advogados e Promotores em processos ali em trâmite ou Cartas Precatórias de outros Juizados. Essa coleta de prova, para o Juizado da Fazenda Pública, por exemplo, pode ser feita inclusive por Conciliador (mais longe portanto de ser considerado ato jurisdicional, ou exclusividade de Magistrado).

É certo que por ser uma figura relativamente nova em termos de "tempo do Direito", há que se sedimentar o que sobre ela se pensa e se formula. A idéia nestas linhas era contribuir a um debate construtivo, pois alguns argumentos contrários se baseiam precipuamente na indelegabilidade da jurisdição (entre outros correlatos), o que se propõe que não acontece de forma alguma (seja qual o entendimento adotado). Sem falar na expressa previsão normativa da existência desse agente, o que precisa ser trabalhado em seu conteúdo, para que a solução não seja um preciosismo da cultura tradicional jurídica, mas algo adequado aos tempos atuais.

Merece destaque, por fim, que o profissional Juiz Leigo é agente que está se posicionando ainda no meio processual, mas sua grande valia, a suma importância de sua existência, capacidade de multiplicação de forças e de absorção de demandas é um grande diferencial a não ser abandonado ou relegado

O Sistema do Juizado Especial, parte do Judiciário reiteradamente apontada como a de maior credibilidade perante a população, somente assumiu essa condição por conter algumas "novidades". Simplificação, novos agentes. Não é apenas essa a tônica de seu "sucesso", mas a concepção de que "mais do 
mesmo" não funciona e não tem funcionado ao longo das reformas do processo comum e até de alguns "ritos". Juizado é mais que isso, é um novo sistema. Uma resposta diferente aos problemas antigos. Uma resposta em que ainda se acredita e que ainda atribui esperança de um funcionamento melhor ao Sistema de Justiça como um todo.

\begin{abstract}
The incoming of the 9099/95 law developed a "microsystem", nowadays, a "Special Courts System". There, beside new ritual, rules and principles delineation, also came a new character: the Layman Judge. The same precept treated about Criminal and Civil procedure. Both of them clearly expressed the Layman Judge and the Conciliator. Both have distinct attributions and qualification, assuming an incomparable importance in this scenario where the acts are not "a new way to do the same". The purpose of this essay is the understanding of the character of the Layman Judge in the criminal field.
\end{abstract}

Keywords: Criminal Special (Small Claims) Courts. Layman Judge. Jurisdiction

\title{
REFERÊNCIAS
}

ASSOCIAÇÃO NACIONAL DOS PROCURADORES DA REPÚBLICA. Nota Técnica PRESI/ANPR/ACA n. ${ }^{\circ}$ 01/2011, de 23 de maio de 2011. Disponível em: http://s.conjur.com.br/dl/associacao-nacionalprocuradores.pdf. Acesso em: 30 mai. 2012.

BRASIL. Constituição da República Federativa do Brasil. Dispõe sobre a Lei Orgânica da Magistratura Nacional. Diário Oficial da República Federativa do Brasil, Brasília, 5 out. 1988.

BRASIL. Lei Complementar n. 35, de 14 de março de 1979. Dispõe sobre a Lei Orgânica da Magistratura Nacional. Diário Oficial da República Federativa do Brasil, Brasília, 14 mar. 1979. 
BRASIL. Lei n. 9.099 de 26 de setembro de 1995. Dispõe sobre os Juizados Especiais Cíveis e Criminais e dá outras providências. Diário Oficial da República Federativa do Brasil, Brasília, 27 set. 1995.

BRASIL. Lei n. 12.153 de 22 de dezembro de 2009. Dispõe sobre os Juizados Especiais da Fazenda Pública no âmbito dos Estados, do Distrito Federal, dos Territórios e dos Municípios. Diário Oficial da República Federativa do Brasil, Brasília, 23 dez. 2009.

ESTADO DE SANTA CATARINA. Conselho Gestor do Sistema de Juizados Especiais e Métodos Não Adversariais de Resolução de Conflitos. Processo Administrativo n. ${ }^{\circ}$ 458162-2012.8.

\section{AGRADECIMENTOS}

Registro a paciente leitura e notas contributivas dos Juízes Humberto Goulart da Silveira e Fernando de Castro Faria, bem como, do Assessor Jurídico Jorge Fernando Flores de Oliveira. Em especial, a atenção de minha esposa Simone com a releitura e a tradução. 